\title{
"O MILAGRE DAS ROSAS VERMELHAS": CORPORALIDADE, FOTOGRAFIA E SACRALIDADE NA MARUJADA DE BRAGANÇA - PARÁ
}

\author{
Helio Figueiredo da Serra Netto ${ }^{1}$
}

Todo mês de Dezembro a cidade de Bragança, no estado do Pará, se organiza em torno de uma das mais importantes manifestações religiosas do estado, a Festa do Glorioso São Benedito - popularmente conhecida como "Marujada". Festa essa que reúne milhares de pessoas, dentre elas Marujos e Marujas de várias regiões do estado que vão em busca de pagar suas promessas, ou simplesmente acompanhar esta importante festividade da chamada "região do salgado". O vermelho - em determinados dias também se usa azul - das roupas é um dos elementos de destaque da cidade, se apresenta como um importante elemento simbólico desta manifestação, ele está presente em vários lugares - dentre as histórias de milagres deste santo, uma delas faz referência a ele ter transformado comida em rosas, ao ser interceptado por seu superior no momento em que levava comida do seminário aos pobres e famintos de sua cidade.

O som das castanholas tocadas pelos marujos aliada a rabeca, ao pandeiro, a dança do "retumbão" dão vida ao colorido que se apresenta na corporeidade e em alguns pontos específicos da cidade, como a Igreja de São Benedito, o "Barracão dos Marujos" e as praças adjacentes. Todos esses elementos se apresentam em uma espécie de sinestesia onde os sentidos se confundem e nos fazem embarcar em uma viagem imaginária onde tempo cronológico é suprimido e somos remetidos ao tempo imemorial - para aludir ao grande mestre Mircea Eliade - onde o sagrado se manifesta e emerge em vários pontos da cidade, seja nos gestos, no som ou no corpo das pessoas que compõem este belíssimo ritual.

Os marujos e marujas apresentam elementos semelhantes em sua vestimenta, como o vermelho que predomina nas cores das roupas e os pés descalços em sinal de pagamento de promessas. Já as castanholas se encontram presentes nos cintos ou nos dedos dos marujos, que se vestem todo de branco e ostentam alguns detalhes em vermelho ou azul - dependendo do dia. Já as marujas ostentam condas, terços, colares e "santinhos" que compõem sua corporeidade, sua vestimenta é composta de uma saia vermelha ou azul, acompanhada de uma camisa branca e um chapéu peculiar. Nos relatos dessas pessoas

\footnotetext{
${ }^{1}$ Universidade Federal do Pará, Brasil.
} 
promessas e graças alcançadas, a festa é resultado da fé em sinal de agradecimento por toda benevolência de São Benedito para com seus fiéis.

A cidade de Bragança é caracterizada por um forte vínculo dos seus moradores com o catolicismo popular que se articula com outros tipos de manifestação religiosa tal como as religiões afro-brasileiras e a pajelança cabocla. A rotina e o fluxo de pessoas na cidade sofrem grande influência das festas de santo e datas sagradas, o elemento de sacralidade é evidente e crucial para o cotidiano bragantino, várias igrejas católicas compõem a arquitetura desta cidade e são rotineiramente frequentadas.

Este trabalho é fruto de uma pesquisa em andamento, que busca fazer uma articulação entre a imagem, a memória e as tecnologias digitais, e tem a fotografia como elemento intermediador da minha perspectiva de intepretação do mundo. Por isso, um dos elementos que se destaca neste ensaio é a presença da tecnologia fotográfica em meio a esta manifestação popular.



A Praça. Foto: Helio Figueiredo da Serra Netto 


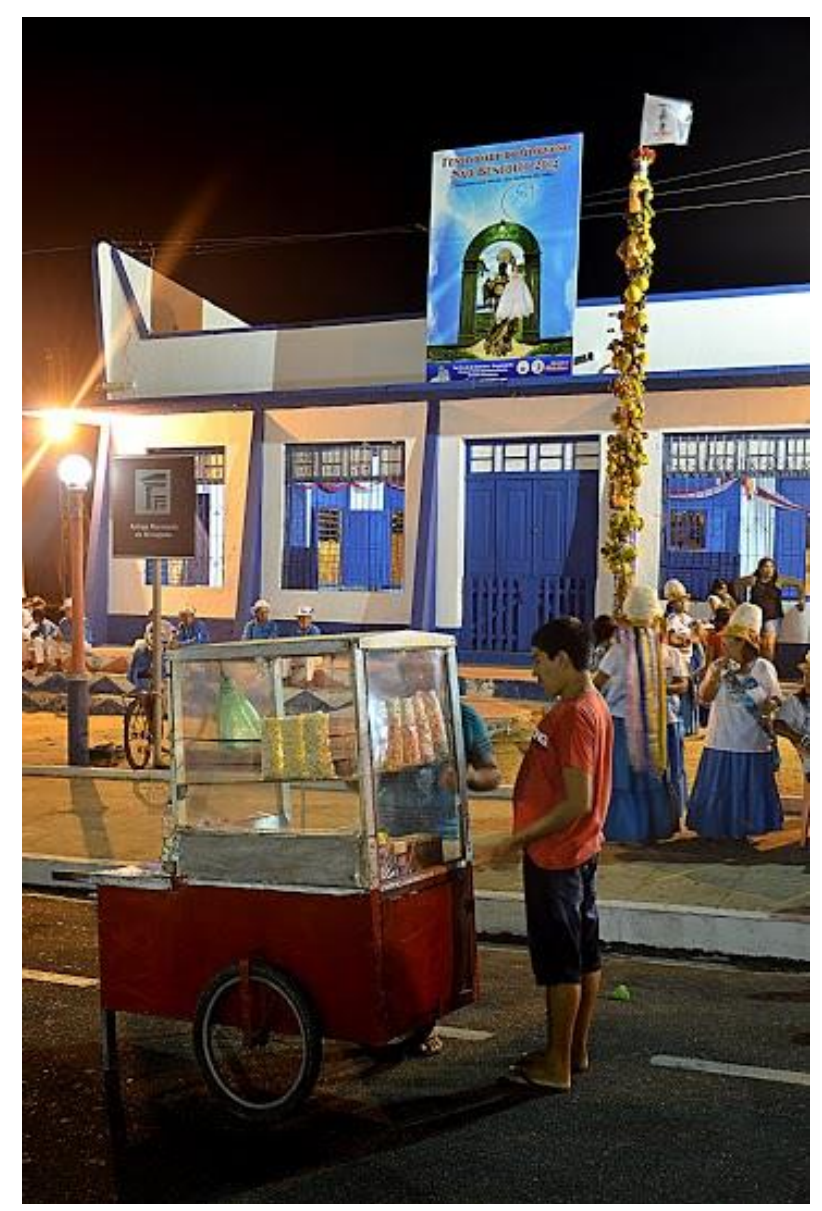

O maestro. Foto: Helio Figueiredo da Serra Netto

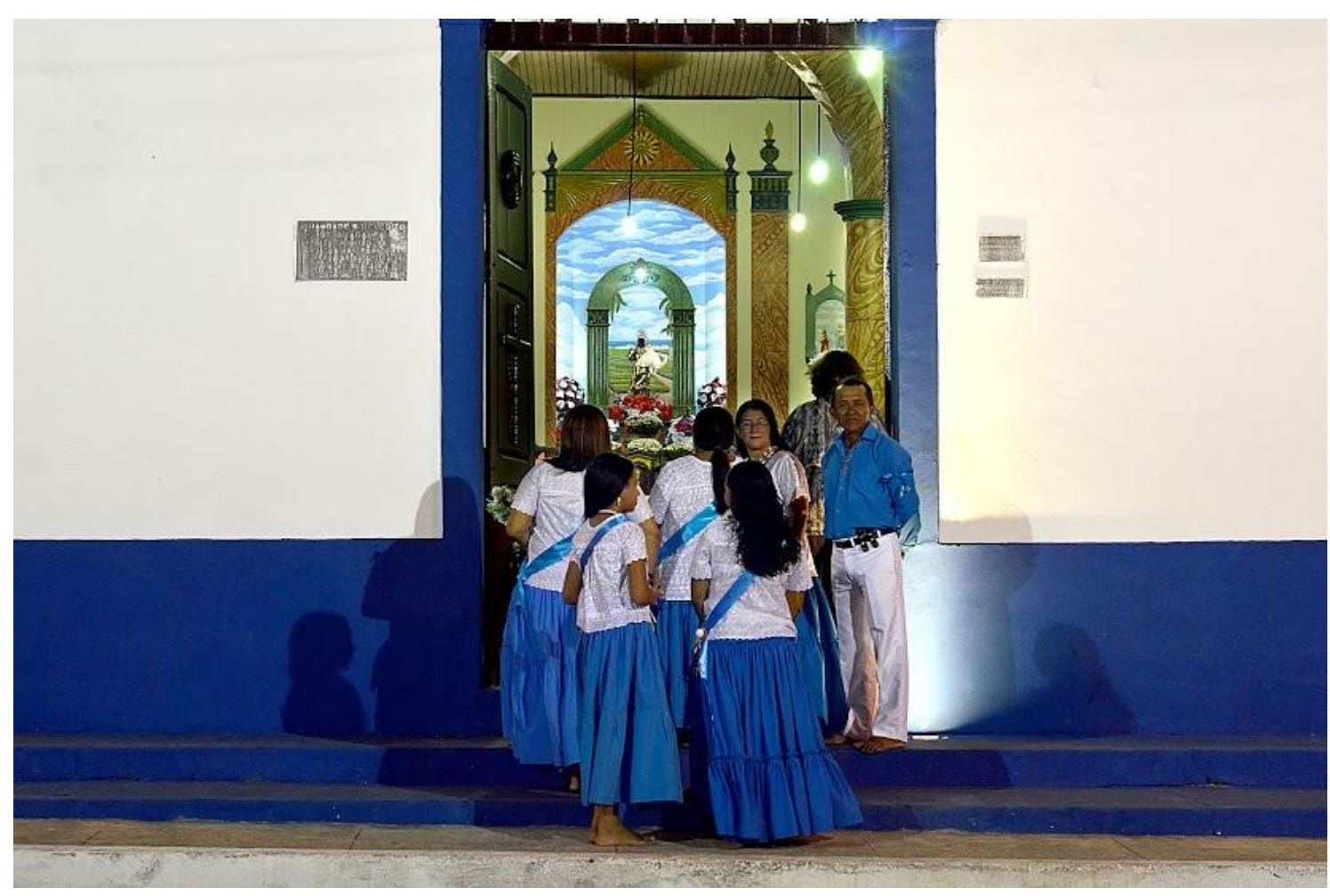

A Igreja de São Benedito. Foto: Helio Figueiredo da Serra Netto 


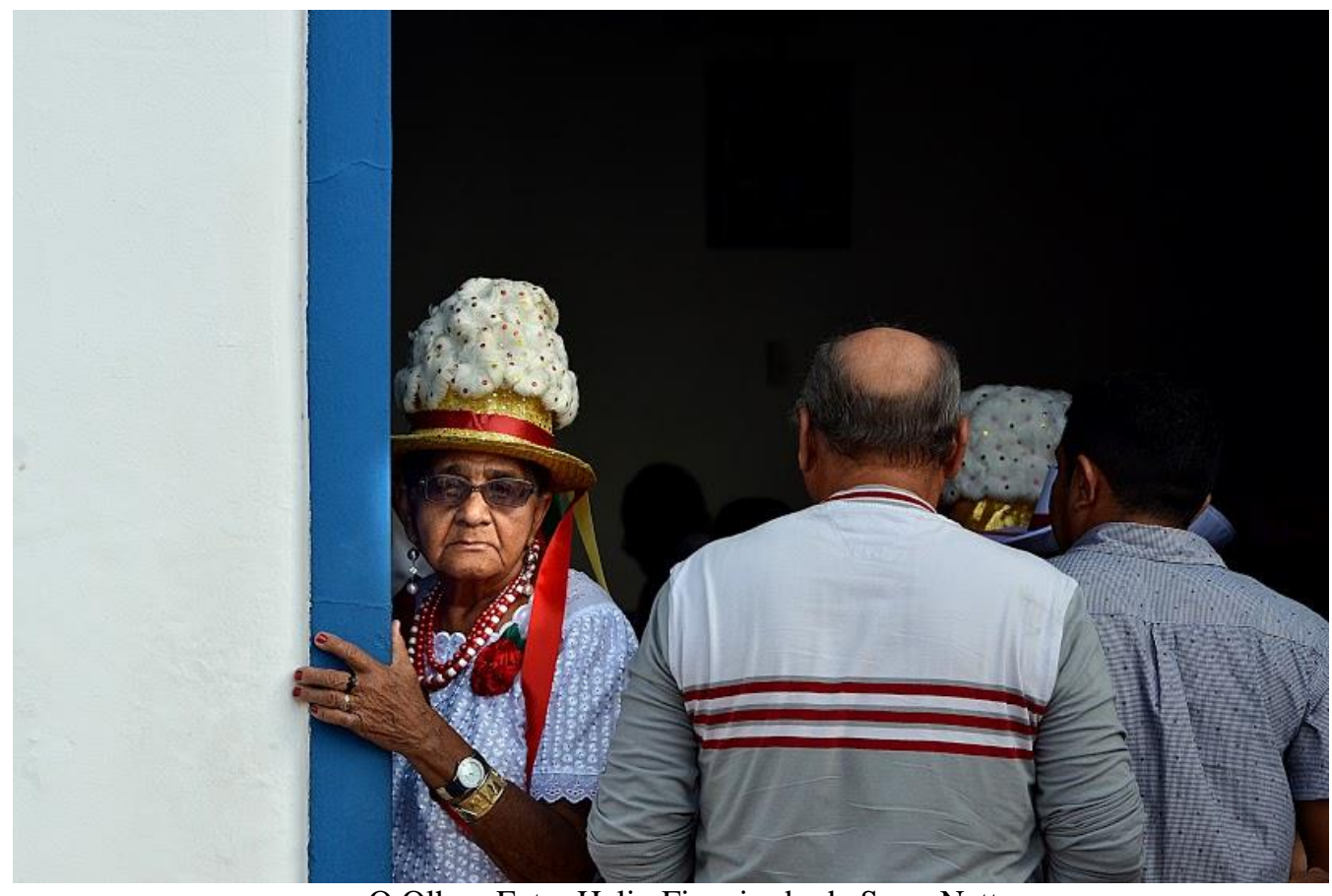

O Olhar. Foto: Helio Figueiredo da Serra Netto

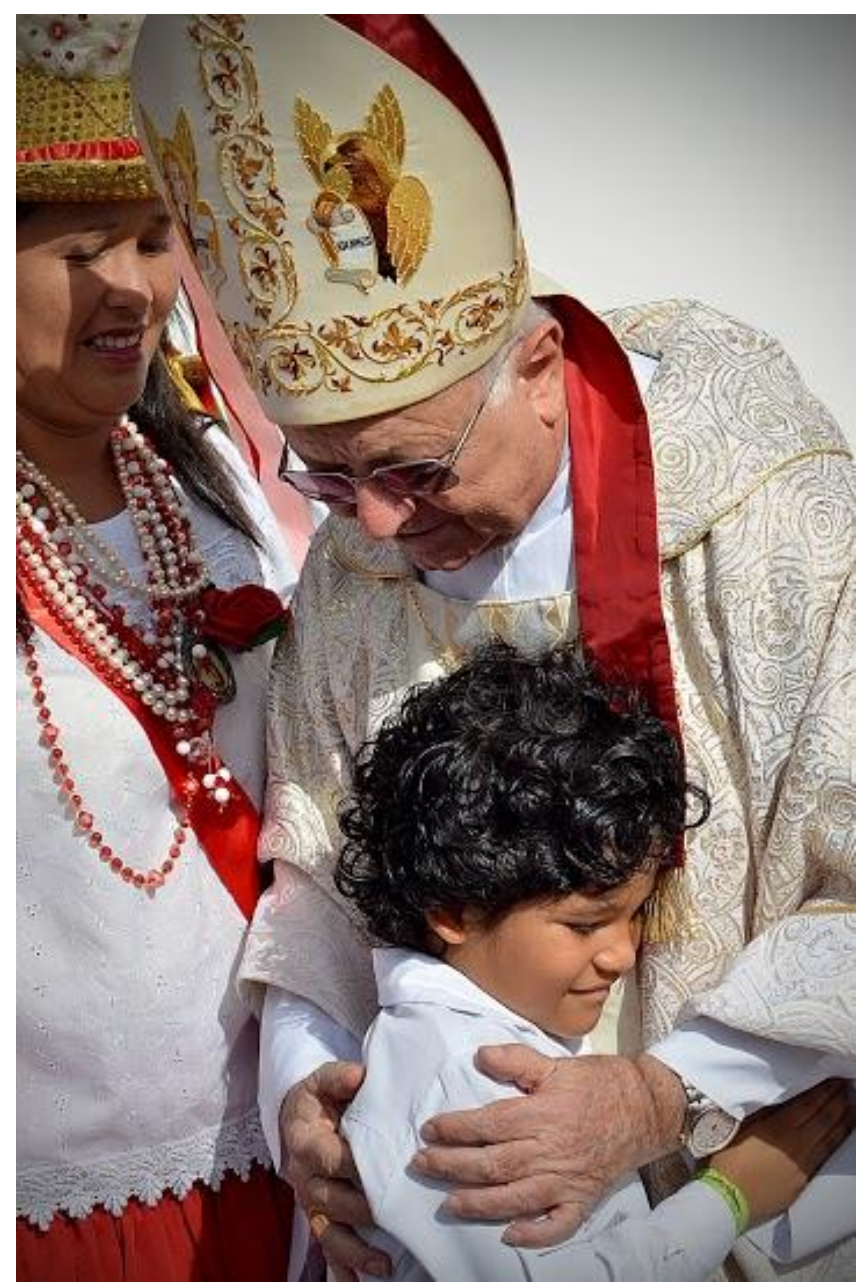

O Bispo. Foto: Helio Figueiredo da Serra Netto 


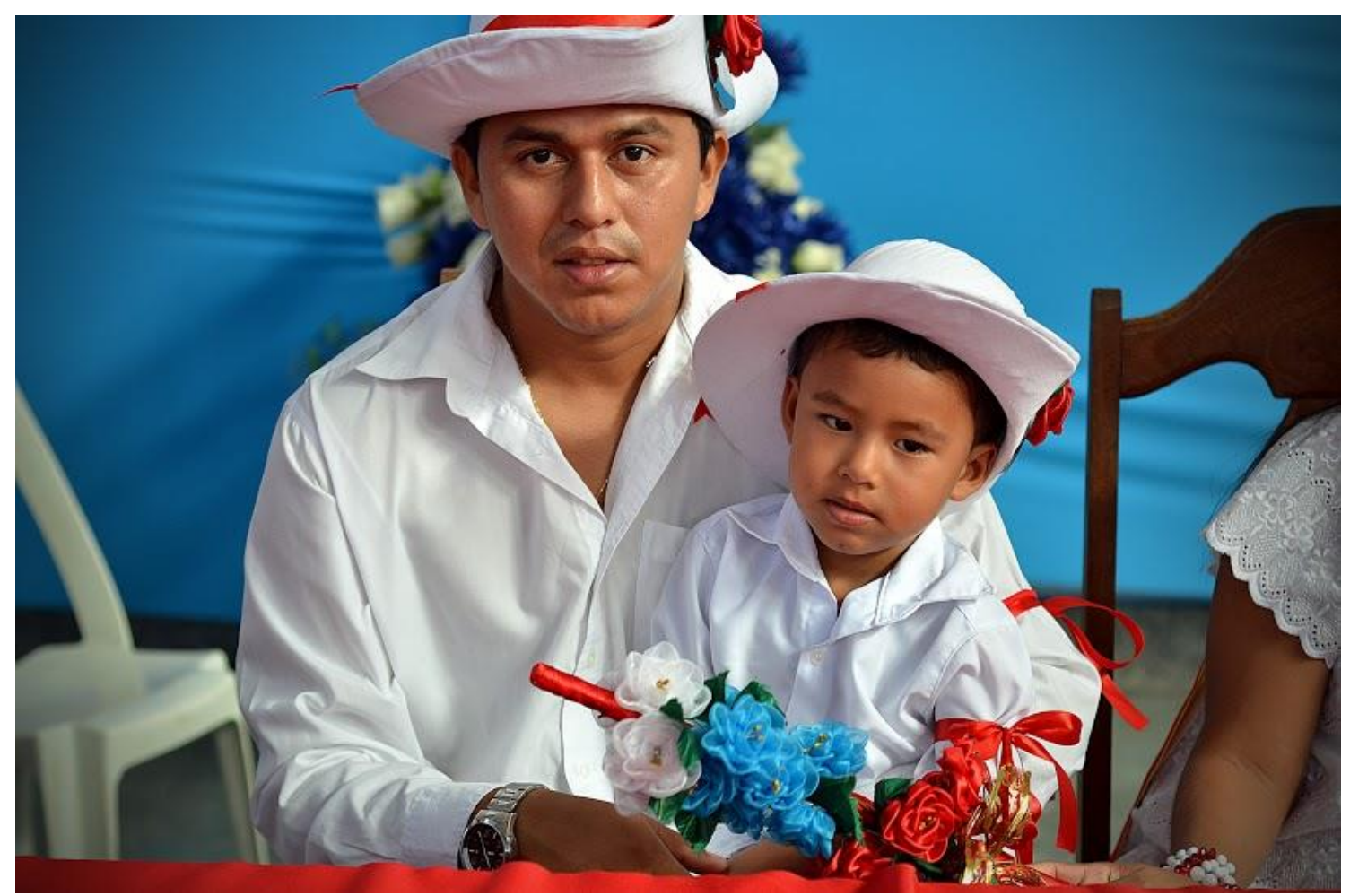

O juiz. Foto: Helio Figueiredo da Serra Netto



O marujinho. Foto: Helio Figueiredo da Serra Netto 


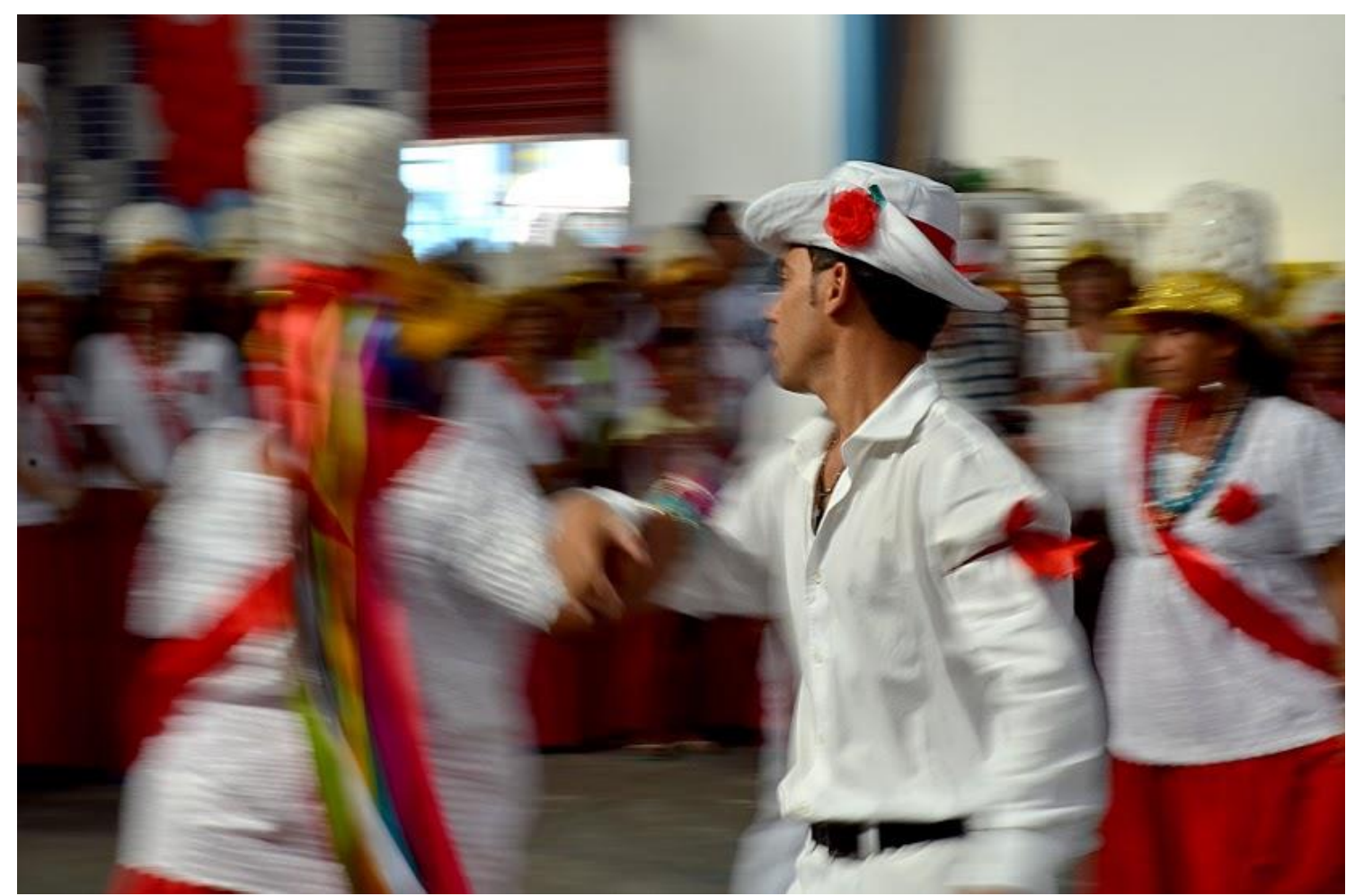

Retumbão. Foto: Helio Figueiredo da Serra Netto



Os músicos. Foto: Helio Figueiredo da Serra Netto 




Marujinho. Foto: Helio Figueiredo da Serra Netto

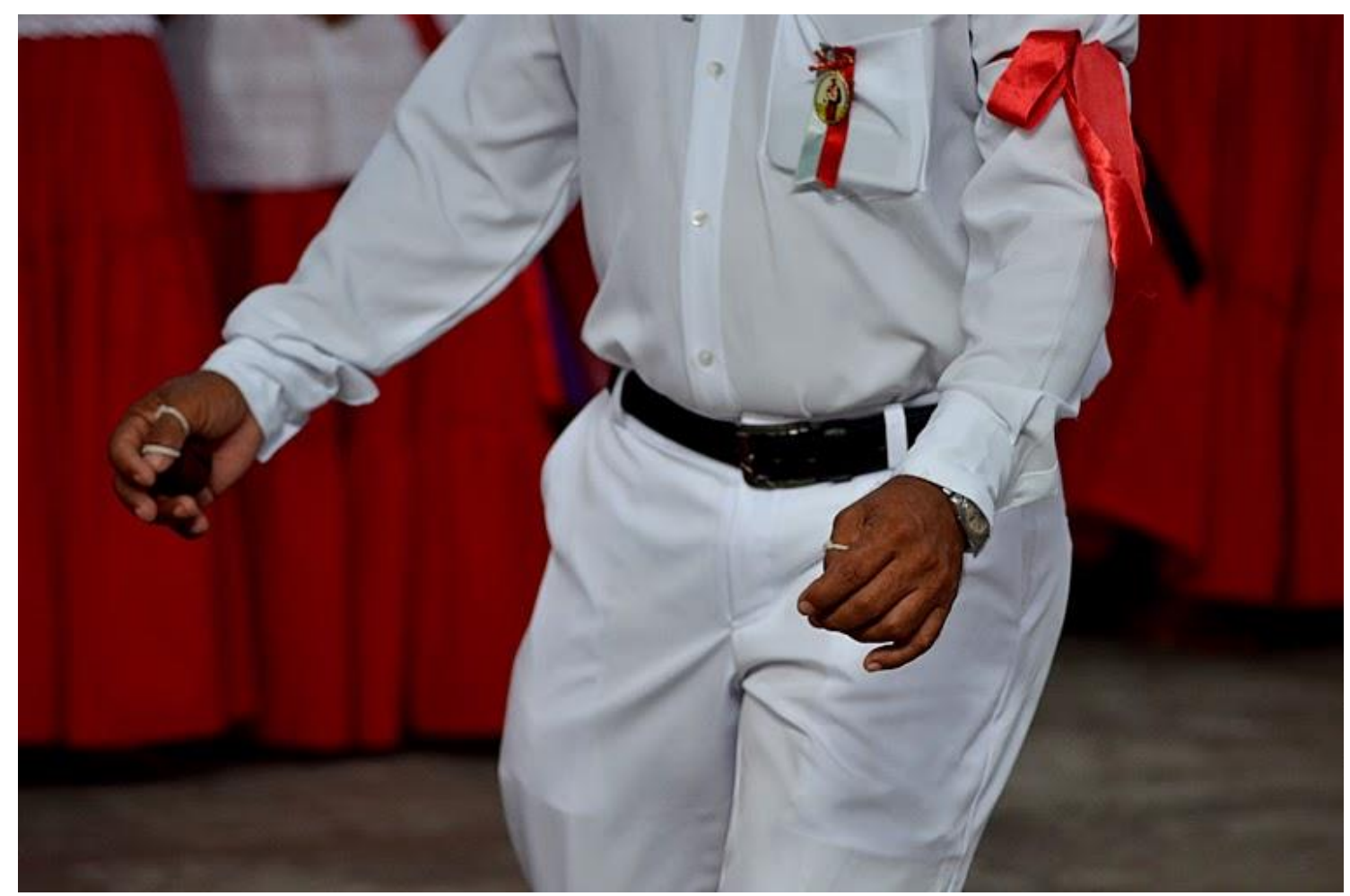

O Som, A Dança. Foto: Helio Figueiredo da Serra Netto 


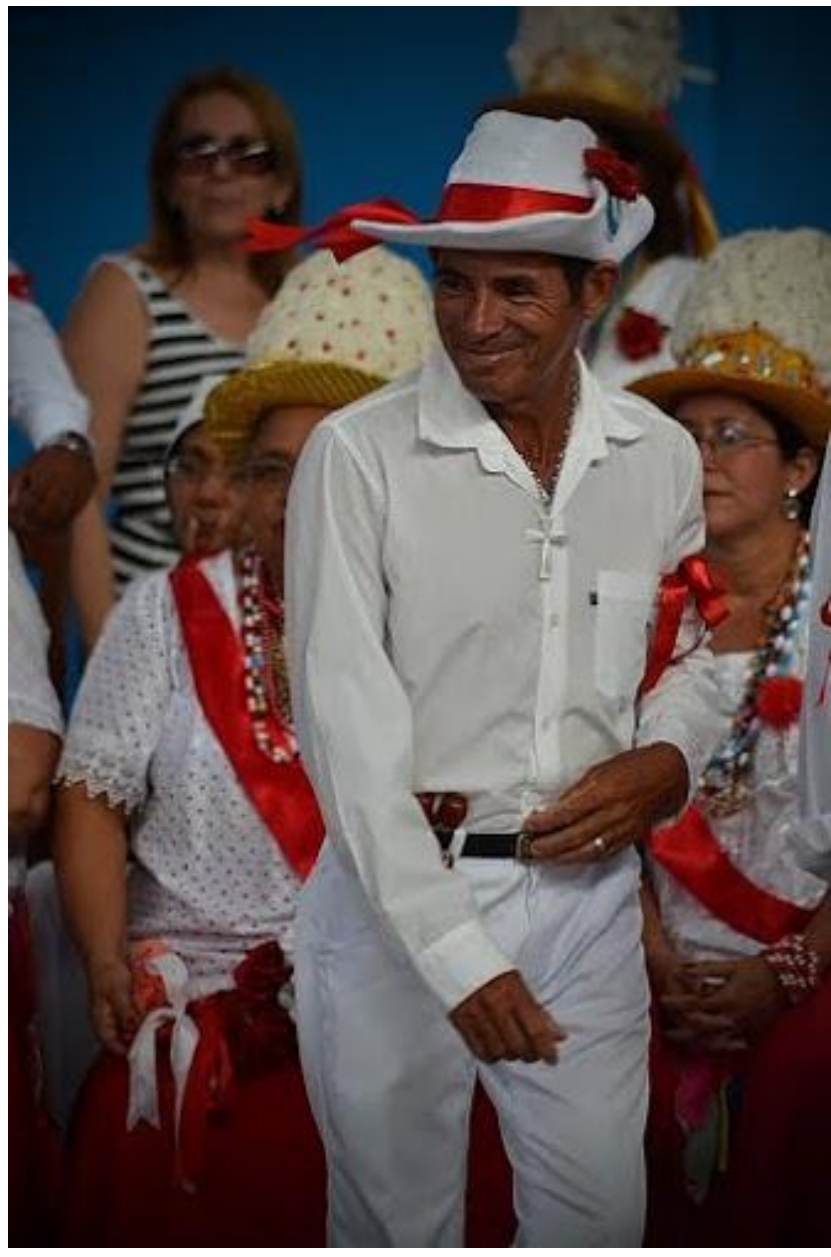

Marujo. Foto: Helio Figueiredo da Serra Netto

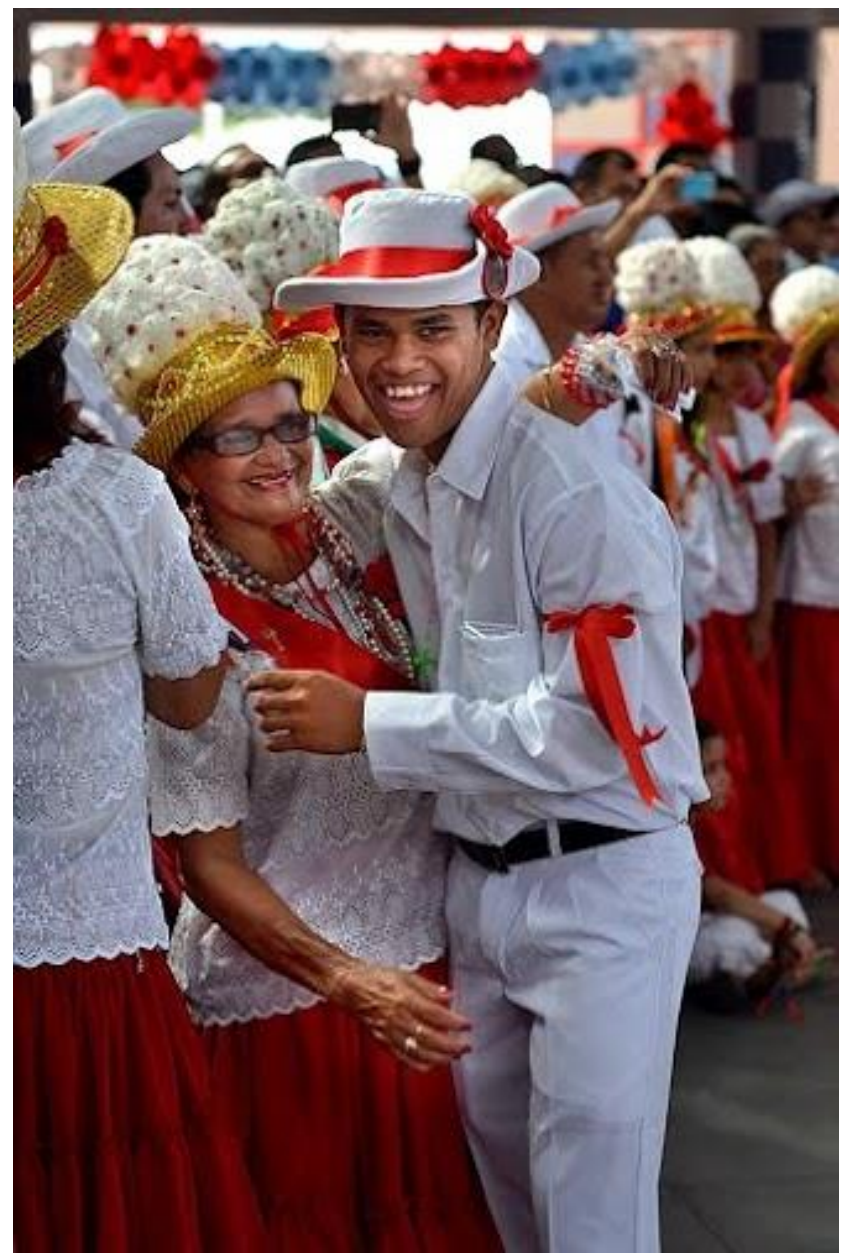

Encontros. Foto: Helio Figueiredo da Serra Netto



O Baile. Foto: Helio Figueiredo da Serra Netto 


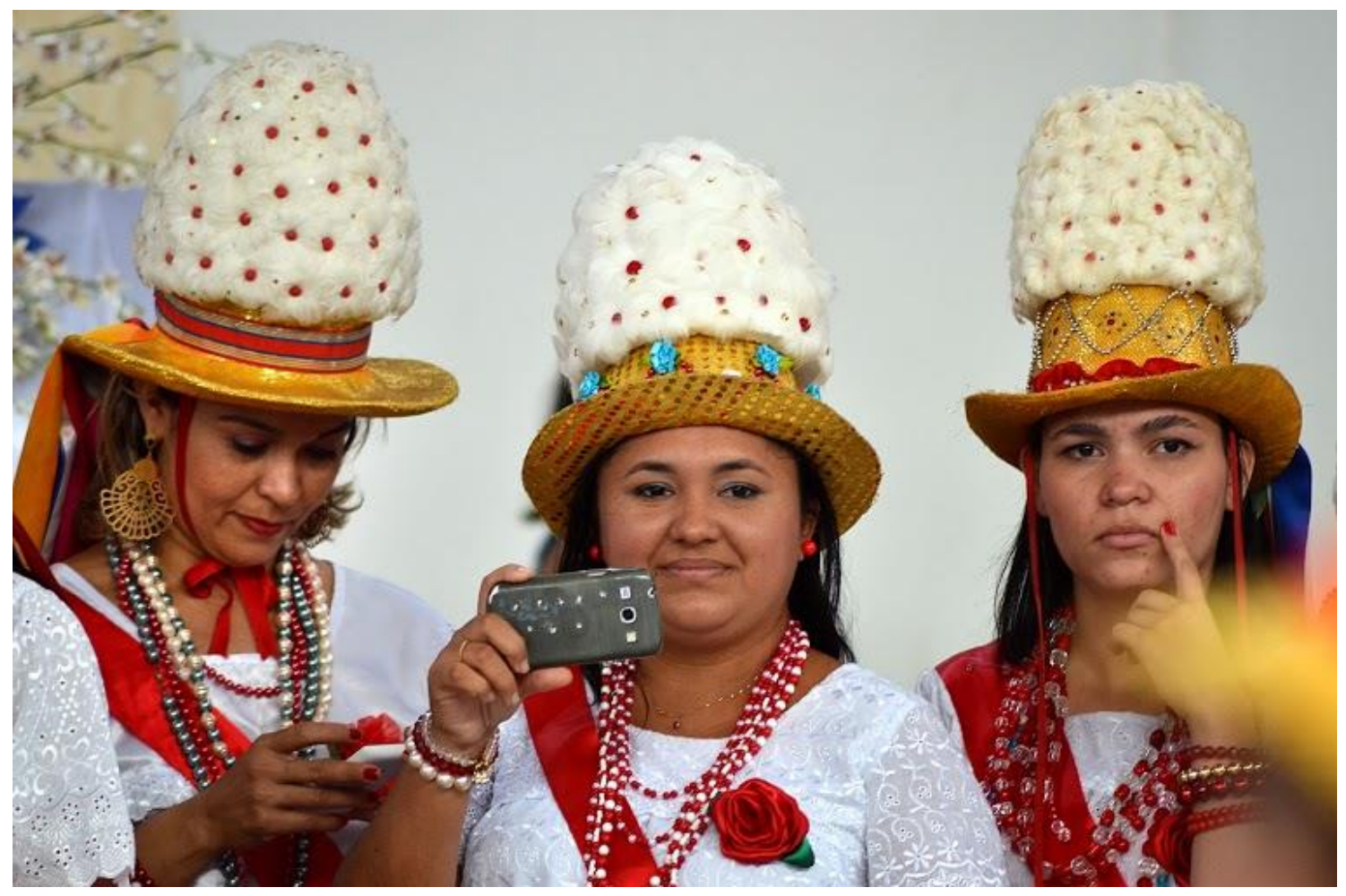

O Registro das Marujas. Foto: Helio Figueiredo da Serra Netto

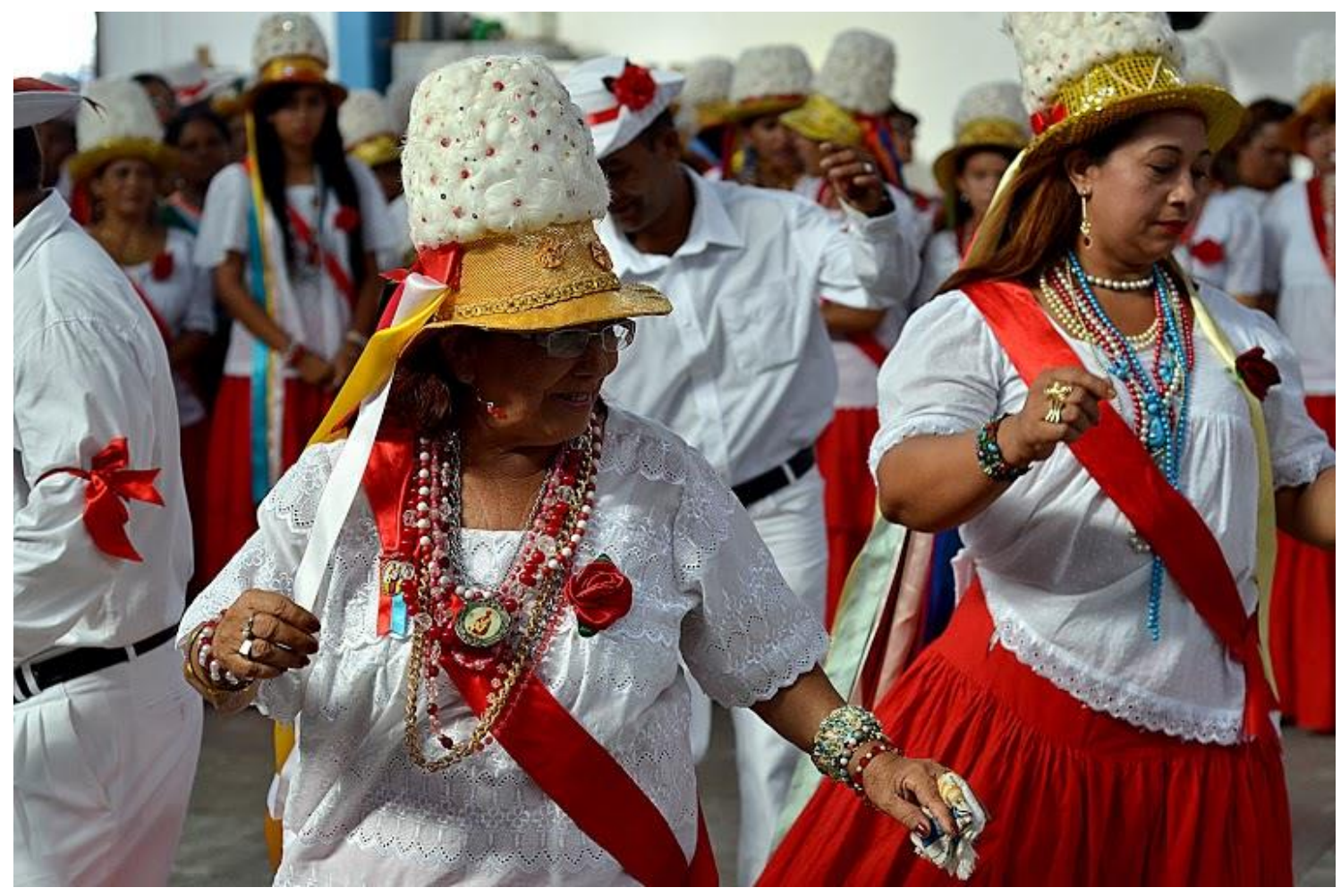

Marujas. Foto: Helio Figueiredo da Serra Netto 


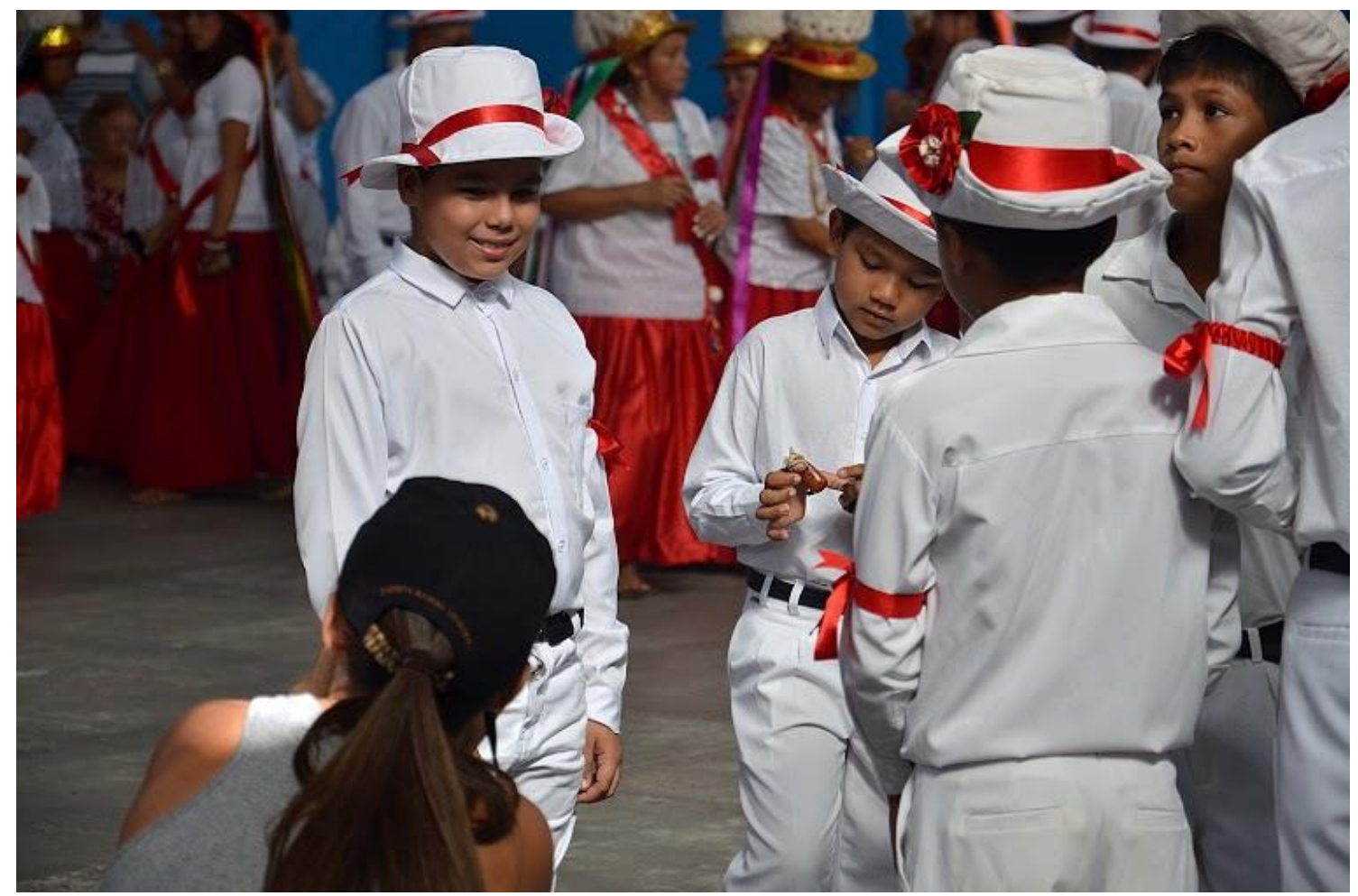

Pose. Foto: Helio Figueiredo da Serra Netto

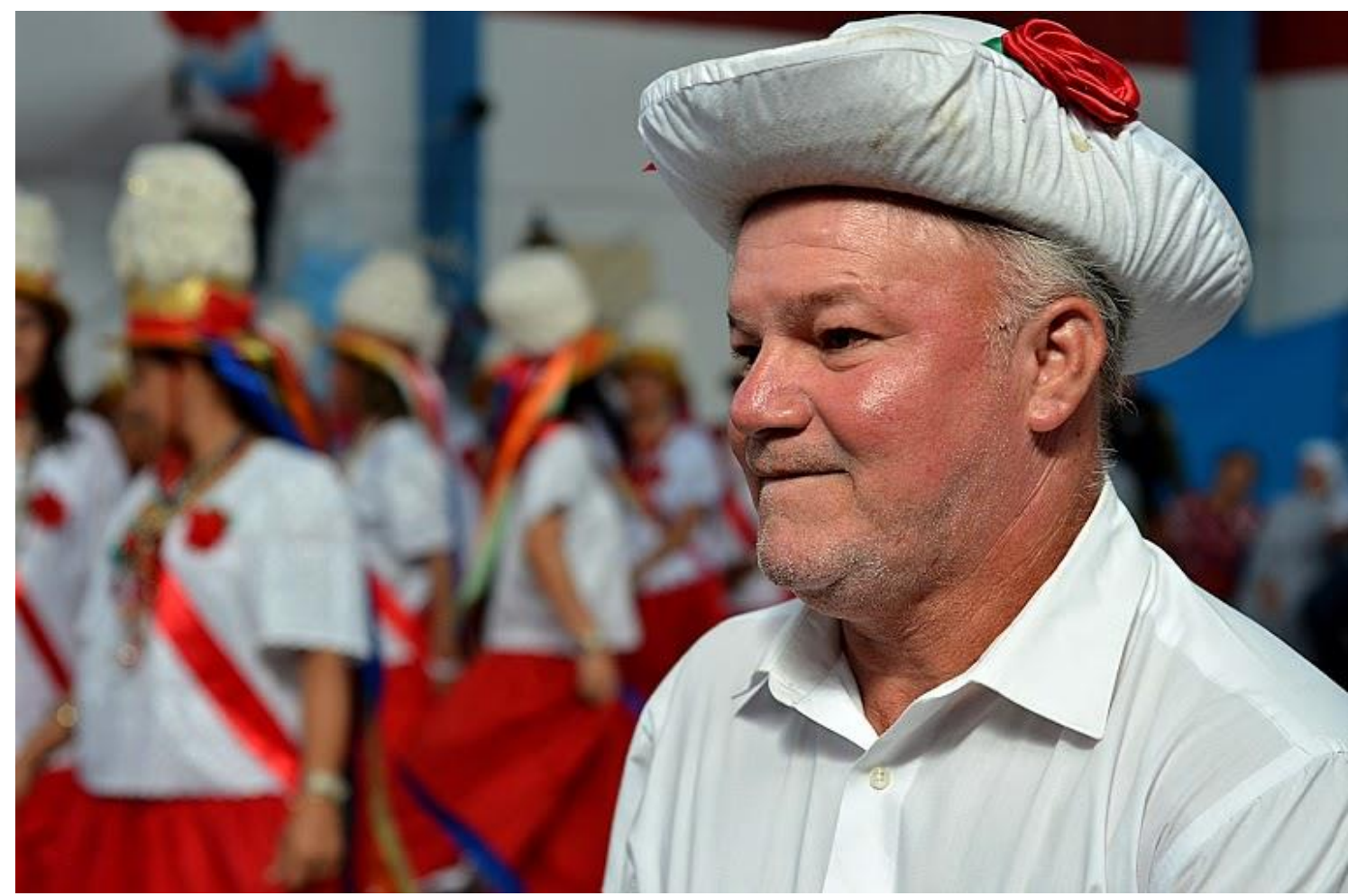

Marujo. Foto: Helio Figueiredo da Serra Netto 


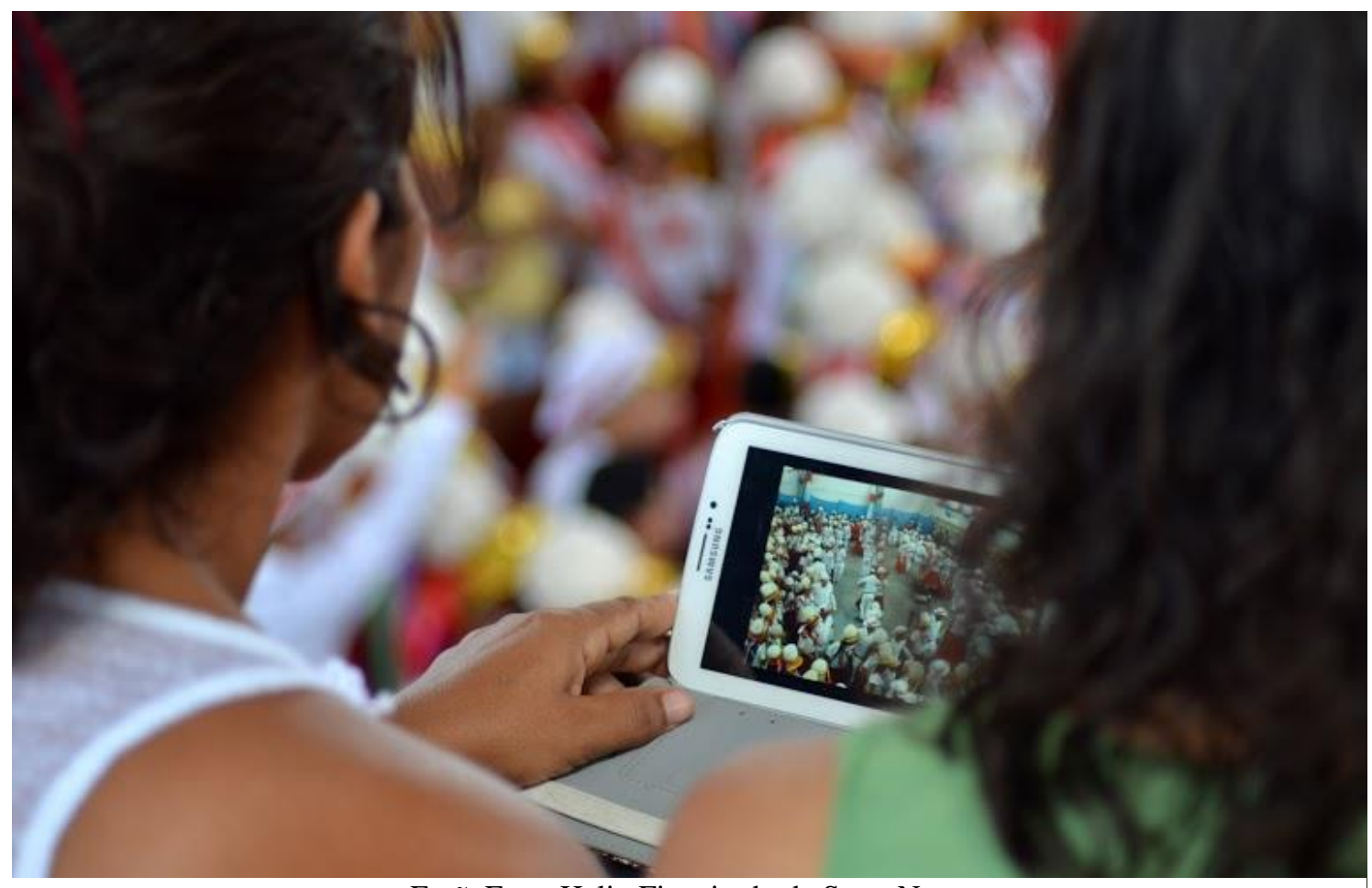

Ecrã. Foto: Helio Figueiredo da Serra Netto

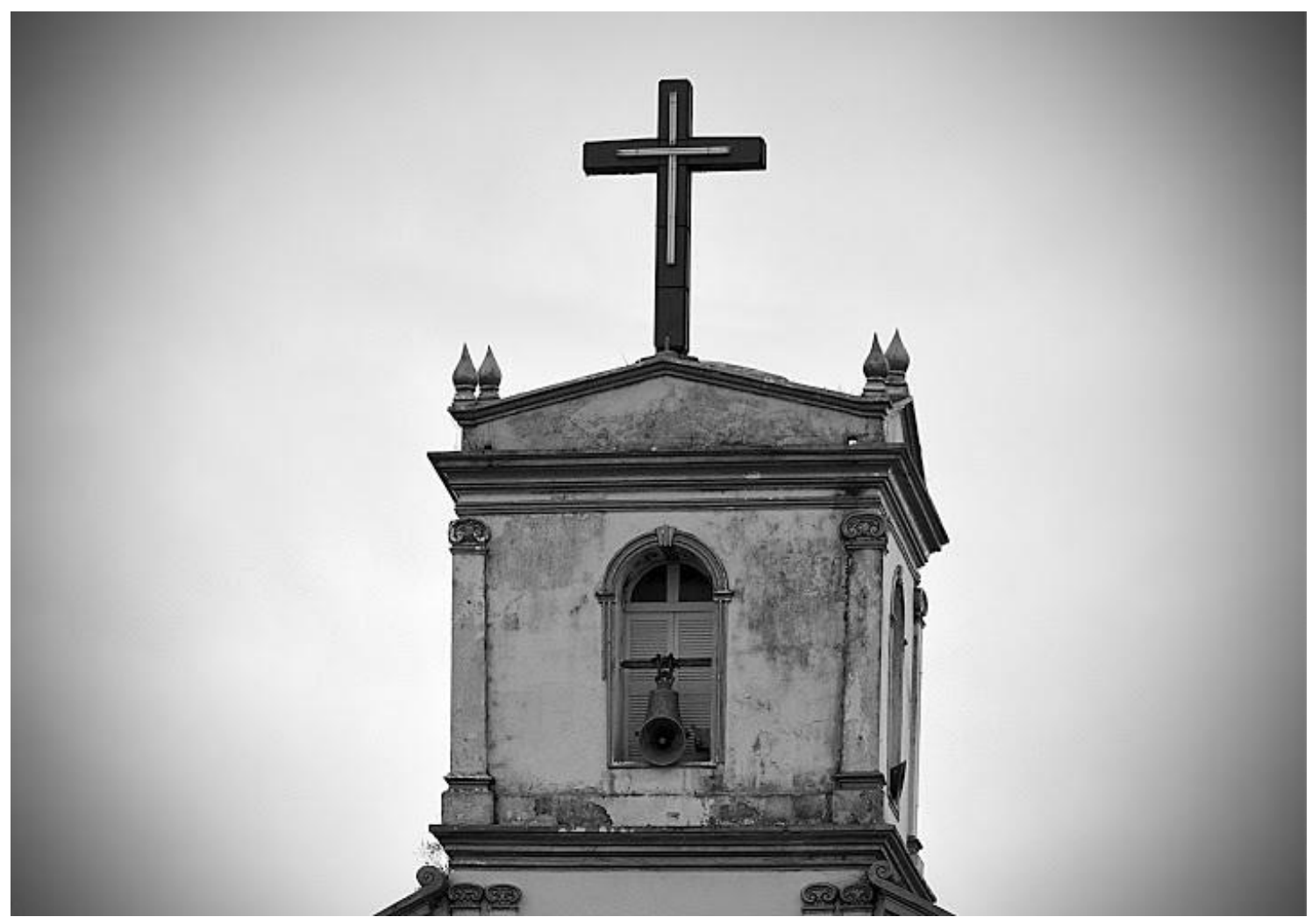

A Esperança. Foto: Helio Figueiredo da Serra Netto

Recebido em: 30/09/2014

Aprovado em: 10/11/2014 